\title{
USO DE LA MENTALIZACIÓN EN EL PROCESO PSICOANALÍTICO ${ }^{1}$
}

\section{USEFULNESS OF MENTALIZATION IN PSYCHOANALITIC PROCESS}

\author{
Peter Fonagy ${ }^{2}$ \\ Chief Executive, the Anna Freud Centre \\ University College of London
}

Palabras Clave: apego; mentalización; investigación; psicoanálisis; psicoterapia

Key Words: attachment; mentalization; psychoanalysis; psichotherapy; research

Vamos a empezar hablando brevemente sobre lo que es la mentalización, su definición, sólo para confirmar que estamos hablando de lo mismo. Posteriormente, voy a hablar sobre las raíces psicoanalíticas de este concepto, y otros aspectos relacionados con el psicoanálisis, para pasar luego a mostrar cómo trabajamos, cuál es nuestra técnica terapéutica a partir de estas concepciones.

La mentalización es una forma de actividad mental imaginativa, que nos permite percibir e interpretar, tanto nuestra propio comportamiento como el comportamiento de otros, en términos de estados mentales intenciones, deseos, creencias, necesidades, sentimientos, etc. Jeremy Holmes afirma que mentalizar significa vernos a nosotros mismos desde afuera, y ver a los otros desde adentro. Tiene que ver con entender los malos entendidos. Por ejemplo, en el contexto psicoterapéutico, cuando existe un malentendido entre el psicoterapeuta y el paciente, que puede implicar una irrupción sobre la alianza terapéutica, de hecho eso suele llevar a un progreso en el análisis, ya que cuando no entendemos a otro entonces tenemos que trabajar más duro para dar cuenta de su comportamiento y es justamente la base del proceso de mentalización.

Tener en mente la mente de los demás, ser consciente de la mente de los demás. La expresión "mindfulness" que proviene de la corriente zen, y que ha tenido un auge importante especialmente en los Estados Unidos, está vinculada a lo que nosotros llamamos mentalización, aunque es un término más amplio.
La mentalización conecta al pasado, el presente y el futuro. No sé si ustedes pueden hacer esto. Pero yo puedo verme al espejo, puedo verme a los ojos en el espejo y puedo recordar cómo era hace 15 o 20 años. ¿Pueden hacerlo? Me resulta mucho más difícil a mí puesto que he cambiado dramáticamente en ese tiempo, pero puedo mirarme a los ojos y recordar cómo era en ese entonces. No me acuerdo de mí físicamente hablando, sino que hago la conexión con mis estados mentales, mis pensamientos y sentimientos en ese entonces, y eso le otorga un sentido de continuidad a mi existencia; y puedo proyectarme a mí mismo hacia el futuro de la misma manera. Imaginen lo que pasaría si no pudieran hacer eso, qué clase de vida tendrían, si no tuvieran ese sentido de continuidad de ustedes mismos. Puede parecer obvio pero es de hecho algo difícil de lograr y desafortunadamente algo que algunas personas no tienen. Me miro al espejo y tengo en mente a la persona que desea levantar el brazo y el brazo se levanta. Un sujeto con intenciones. Un pensamiento puede llevar a una acción. Estamos, de esta manera, creando una coherencia fenomenológica, que es tan inmensamente preciada para darle un sentido, un significado a nuestra persona, a nuestra vida. $Y$ esto, que podemos asumir como de Perogrullo, no es tan simple ni tan fácil.

Me gustaría, ahora, que hiciéramos un pequeño test; es un test sobre mentalización. Miremos esta imágenes, ¿qué expresión tienen estos rostros? ¿amigable, triste, sorprendido o preocupado, seguro de algo, bromista o con- 
tento, convencido, conmocionado o deseo,...? Bien. Ahora, pónganse en mis zapatos. (muestra fotos de una escena de un partido de football) Julio del año pasado, los Estados Unidos están jugando contra Inglaterra el campeonato mundial de football. Inglaterra, nosotros inventamos el football. Los estadounidenses usan el término football para algo totalmente distinto. Llaman así a un deporte raro. Y ése es Robert Green, y el otro es un atacante que ni siquiera conozco, patea la pelota que hasta yo podía haber pateado más fuerte, y Robert Green la deja entrar. Increíble. Y ahí está su foto después de eso. ¿Está angustiado, enojado, desilusionado, frustrado? Ahora, ¿qué tiene eso que ver con la mentalización?

Al mismo tiempo, los hinchas ingleses, no podían evitarlo (se muestra una foto). Tienes que tener la capacidad de ponerte en los zapatos de la otra persona. Nuestros cerebros están construidos de esa manera. $Y$ no es sorprendente, dado que los pensamientos sobre nosotros mismos, nuestros estados mentales, y los pensamientos sobre los estados mentales de los demás, ubicados a nivel cerebral, se sobrepongan. Las áreas blancas en la diapositiva indican las representaciones de nuestros propios estados mentales y las de los demás estudiados por numerosas investigaciones. Y lo que deberíamos de poder ver a partir de esto es que las áreas de hecho, cortex medio prefrontal, la unión entre los lóbulos temporal y parietal; sobreponen. Propias y ajenas, Pero ¿por qué debería de ser así? ¿por qué deben ubicarse tan cercanamente? Tanto que si pensamos en nuestras madres, lo que ella prefiere y lo que a ella le gusta, y su comida favorita y después pensamos en nuestra comida favorita, ¿por qué debería activarse la misma parte del cerebro?

Eso nos dice algo sobre el origen de esta capacidad para visualizar la mente de otras personas y las nuestras propias. Básicamente, y a nivel del desarrollo, las dos funciones están encadenadas, y como, estoy por mostrarles, nuestra capacidad de representar nuestros propios pensamientos se ve afectada por cómo nuestros pensamientos son percibidos por otros, acá es donde el sentido psicoanalítico del concepto de mentalización tiene lugar.

Ahora voy a hacer un poco de recorrido histórico para tratar de mostrarles dos cosas: en primer lugar que el concepto de mentalización está en la base de la teoría freudiana, y en segundo lugar que aún estando en la teoría, no es una técnica freudiana. La gente ha sido quemada en la hoguera por salirse de los postulados freudianos. Espero sobrevivir esta tarde.

Una de las críticas más comunes contra la mentalización es que sólo es un término desagradable para describir lo que Freud, Bion, Winnicott y Marty han expuesto. Nunca hemos sugerido lo contrario. Hemos literalmente dicho que la mentalización es el concepto menos original en el diccionario de términos psicológicos. En nuestro libro publicado en 2006, afirmamos que el tratamiento basado en la mentalización es el abordaje terapéutico menos novedoso imaginable que hay, simplemente porque gira en torno a la capacidad humana más fundamental; de hecho, la capacidad que nos hace humanos.

Hemos sido muy honestos, ¿podría haber algo más honesto que eso? ¿Qué el afirmar que no estamos tratando de decir nada nuevo? Sin embargo, eso no ha impedido que la gente diga -nadie en este recinto, estoy seguro- que esta mafia de la mentalización está diciendo exactamente lo mismo que $x, y$ y $z$ han dicho ya. Lo que se resulta muy extraño, porque paradójicamente, aunque afirman que estamos diciendo lo mismo, también dicen que estamos completamente equivocados. Esa gente afirma, lo que sea que ustedes estén afirmando no es nuevo, y lo que es nuevo, no es cierto. Así que es difícil para nosotros. Estamos tratando... lo que quisiera comunicarles hoy, si hay algo que quisiera que les quedara grabado hoy, es que ninguno de nosotros cree que está tratando de proponer una escuela psicoanalítica o psicoterapéutica nueva. Ya existen demasiadas escuelas y no necesitamos más. Lo único que estamos tratando de decir es que para ciertos pacientes, cuyos problemas ustedes pueden formular siguiendo esta propuesta, ésta técnica les permite ayudarlos más que usando otras técnicas. Es una nueva técnica, no una nueva teoría. Y para probar este punto, voy a aburrirlos por 25 minutos, para explicarles por qué no es una nueva teoría y por qué todo lo que nosotros estamos planteando ya ha sido planteado por otros anteriormente. ¿Sí? Esta es una estrategia defensiva, como ustedes comprenden.

Lo primero a lo que quiero hacer referencia es al concepto freudiano de ligazón. El concepto de ligazón fue considerado por Freud como un cambio cualitativo desde el impulso a la actividad asociativa, y es dicha capacidad de asociación la que libera al paciente del compo- 
nente físico del impulso. Llevar los impulsos a un nivel de representación, convertirlos en algo mentalizado es lo que libera al paciente de su demanda física. Esto es probablemente un llamado al insight, en los trabajos tempranos de Freud, en los que él se refiere al pensar como una protección contra la acción por decirlo así. El pensamiento está como conteniendo a la acción, lo que provee una vía realista de cauce para los impulsos en ausencia de un objeto necesario y gratificante. Así que si frente a la presión del impulso, puedo imaginar, mentalizar eso me puede liberar de la necesidad inmediata de buscar una satisfacción.

Freud, y esto es mucho menos conocido, en el proyecto antes de convertirse en analista propiamente dicho, reconoce que la mentalización era de hecho una actividad social, relacionada con el prójimo, a través de la cual el individuo aprende a ser consciente de sí mismo. Esto es de hecho, y voy a volver sobre este punto más tarde, un aspecto clave para entender la mentalización. Evolutivamente hablando, todo se reduce a nosotros siendo capaces de estar juntos, en un grupo como éste, y ser capaces de experimentar las vivencias de los demás hasta cierto punto. Lo que quiero decir es, imaginen ese gol que Robert Green no atajó, si todos los hinchas ingleses nos hubiéramos sentido distinto al respecto la repercusión de esto hubiera sido diferente, pero todos sentimos "Ay, Dios mío" y eso fue lo que nos unió, lo que nos dió un sentido de cohesión.

Melanie Klein propuso un concepto que está muy vinculado a todo esto: la posición depresiva. Cuando ella emplea este concepto, a lo que se está refiriendo es al reconocimiento del dolor y el sufrimiento de otra persona. Que el niño, en un momento determinado, desarrolla su capacidad para entender lo que la otra persona está sintiendo; esto constituye un mojón en el desarrollo individual. La experiencia de vivenciar mentalmente a un otro, fue pensada por los freudianos, en los tiempos de grandes discusiones y controversias, en las que bombas caían sobre Londres, y los psicoanalistas discutían si el complejo de Edipo tenía lugar en las primeras etapas de vida o después de los 3 años, en medio de una guerra de grandes dimensiones como la Segunda Guerra Mundial.

Resulta que, como investigaciones posteriores probaron, los freudianos tenían razón acerca del momento en el que el niño comienza a ser consciente del mundo psíquico de los demás, que es de hecho en la primera mitad del primer año de su vida. No voy a profundizar en esto ahora, ¿capaz que durante la discusión después?

Así es que Bion también reconoce que el tránsito de la posición esquizo-paranoide a la depresiva pasa por la ligazón de los impulsos e implica necesariamente la contención e involucramiento de otro: de la madre. $Y$ lo presentó sugiriendo que la experiencia interna vivida pasivamente se ve transformada en una experiencia tolerable siempre que pueda ser pensada, al comienzo por la madre y recién después por el niño. Esto es lo que el llamó el desarrollo de la función alfa. Y su propuesta es muy próxima a lo que pasa en la realidad, es decir, que nuestros cerebros en cierto momento, y a partir del vínculo con otro, desarrollan la capacidad de transformar la experiencia física en una psicológica. El lo plantea de una manera brillante y destacada, diciendo que la capacidad para tolerar la frustración (o sea para controlar la reacción espontánea frente a la necesidad) es lo que le permite a la psique desarrollar el pensamiento, lo que a su vez va a transformar esa frustración en más tolerable. Lo que él está diciendo es que al poder mentalizar la vivencia se vuelve tolerable, permitiéndole al sujeto que la mentaliza, saber qué es lo que está sintiendo y eso hace que la experiencia sea soportable. $Y$ esto, que Bion capturó, es lo que yo considero la esencia de la psicoterapia psicológica. Seguiremos hablando de eso más adelante. Bion fue también un adelantado a su tiempo al conectar dicha capacidad con la diada madre-infante.

Donald Winnicott es otro autor fundamental para la mentalización. Algunos dudan que hayamos ido más allá de Bion y Winnicott. De Winnicott quiero destacar su concepto de espejamiento maternal, que es la base de lo que nosotros llamamos el self mentalizado. Y lo que tan brillantemente plantea este autor, es que lo que el cuidador necesita hacer es comprender psicológicamente al infante para que, al sentirse comprendido y explicado, el sentido auténtico del self del pequeño emerja. Permítanme darles un ejemplo de esto, de mi propia experiencia. Este fue un momento "Eureka" para mí, o al menos es lo que creo pensando en retrospectiva. Mi hijo estaba sentado en una silla alta para bebé, jugando con un tenedor plateado, no sé por qué, pero estaba jugando con él. Bueno, en ese momento tenía menos de un año y era un poco torpe, y tiró el tenedor. En ese instante 
me di cuenta de que estaba señalando un vaso lleno de agua mientras hacía un ruido como: iiiii, iiiii, iiiii. Mi esposa se agachó y levantó el tenedor, y se lo dio de nuevo. Aunque ella no siguió toda la secuencia, yo sí, y sin embargo no me cayó la ficha que él estaba señalando el vaso, que también era un objeto brillante, para comunicarle a mi esposa que quería el tenedor de vuelta. ¿Ven a lo que voy con esto? Que yo soy el padre y ella es la madre. Mi cerebro no funcionaba de la misma manera que el cerebro de ella, no hacíamos las mismas conexiones con respecto al niño, no lo teníamos en mente de la misma manera. Yo miraba desde afuera, no desde adentro de la mente del niño. Pero una vez que vi lo que mi esposa hacía, estuve firme ahí, diciéndole, ¡bien ahí!

Winnicott, que estoy seguro que también era padre, probablemente no podía cumplir esa función sólo, pero sí pudo escribir al respecto. Él escribe sobre esto, sobre que el self psicológico se desarrolla después de que el infante experimenta el ser percibido por su cuidador como un ser pensante; la vivencia de mi hijo como un ser que necesita algo, surge en parte a raíz de que alguien percibe que él necesita algo. $Y$ es entonces que el deseo por tener algo se convierte en un estado tanto psicológico como físico. Esta es la clave de la propuesta winnicottiana. Asimismo, la contraparte de esto es que si no se tiene la vivencia de una madre como mi esposa, o de manera más amplia, de una madre que percibe y refleja los estados internos del infante, que espeje las experiencias del mismo, sus estados internos, un aspecto central de la constitución psíquica del sujeto estará ausente.

Observando la evolución de niños, específicamente huérfanos rumanos, que no tuvieron estas bases puesto que sufrieron de negligencia severa, y que ahora, en la adolescencia, aún no pueden lidiar con sus estados internos y necesidades, aún se sienten rebasados por sus emociones y por lo que llamamos disregulación afectiva, que es lo mismo que decir que no pueden mentalizar sus pensamientos y sentimientos; las actúan, no pueden unirlos. Este es un aspecto que para nada puede ser considerado trivial en el desarrollo humano.

Lo que hemos visto hasta ahora en el psicoanálisis, es que el progreso en nuestro entendimiento de la mentalización está relacionado con las relaciones objetales, y claramente con la relación madre-infante. Esto no significa que se requiere necesariamente de un padre o ma- dre, es suficiente si existe un hermano mayor que te mentalice. Es más, probablemente sea suficiente el sólo vivir en comunidad, siempre y cuando exista alguien lo suficientemente preocupado por tus estados subjetivos como para espejarlos. Nuestra tragedia como especie es que debido a la invención del tren, de la máquina de vapor, la unidad de la comunidad se vio resquebrajada y no se prioriza en ella el entendimiento mutuo. Hemos roto la cadena lógica de las familias unidas en un solo sitio, de genes interesados en perpetuarse, y por lo tanto, en entender el mundo subjetivo de las personas unidas por vínculos sanguíneos. Ahora vivimos en edificios con muchos pisos, con gente que no está genéticamente relacionada con nosotros y de quienes no nos importa su vivencia subjetiva. Y esto está de hecho afectando un proceso evolutivo que la ingeniería social no ha logrado resolver aún...Sé que es domingo, y he estado desafiándolos, pero trataré de contenerme.

Mientras tanto, en un escenario psicológico completamente distinto, en París, un puñado de analistas que no aprobaban ni creían en la teoría de relaciones objetales de hecho fueron los creadores del concepto de mentalización y lo llamaron mentalization (en francés). Personalmente creo que si yo hubiera nacido en París, no hubiera sido tan difícil para la mentalización en el ámbito psycho; suena mucho mejor mentalization en francés que en inglés. Los psicoanalistas franceses inventaron el constructo a partir de investigaciones básicas sobre medicina psicosomática. Lo que ellos vieron fue algo que denominaron pensamiento post-operatorio o pensamiento concreto; la idea básica era que existe un sistema que la mente requiere para contener al ser físico. La parte física librada a sí misma, podría llevar a la ansiedad, a la desintegración, y para poder controlar eso, para mantener esta parte integrada, se necesita de un conjunto de experiencias organizadoras, que se reflejarían en representaciones de esos estados y en ellos basaríamos nuestra subjetividad.

Y es esta subjetividad la que nos permitiría disfrutar de la libertad que todos tenemos para emplear la asociación como medio para transitar de un pensamiento a otro, pero al mismo tiempo asegura la estabilidad de la que hemos estado hablando hasta ahora. Y Pierre Marty escribió sobre este tema, de una manera muy clara en los años sesenta.

Luket escribió al respecto desde un punto de vista del desarrollo, así que nosotros ni 
siquiera fuimos los que inventamos el aspecto del desarrollo de esta propuesta, puesto que Luket escribió al respecto en términos de varias fases organizadas por las que la mentalización atraviesa, durante el desarrollo infantil. Dicho desarrollo se da primero en lo que él llamó mentalización primaria, que de hecho implica la ausencia de mentalización, de la que hablaremos, después en la mentalización simbólica secundaria, donde existe una conexión más cercana entre los datos sensoriales (pensada en términos de fantasías inconscientes) y el contenido de índole mental y pensamientos de tipo verbal, que sus proponentes sostienen como ya una fase de mentalización total. Mi perspectiva al respecto es ligeramente distinta desde el punto de vista del desarrollo, aunque digamos que la trayectoria descrita se asemeja bastante a la mía.

Así que, habiendo expuesto lo anterior, ¿cuál es nuestra contribución? Todo lo que hemos mencionado fue dicho por Freud, Klein, Bion, Winnicott, por el grupo psicosomático de París. Y ustedes se preguntarán ¿qué hacen estos sujetos de la nueva mafia mentalizadora? No lo sé...

Bueno, pusimos en escena a la teoría del apego; esa es nuestra contribución. La teoría del apego es algo maravilloso. Como ustedes saben, es la teoría de Bowlby, y es la que conglomera a las distintas vertientes psicoanalistas británicas; porque los freudianos, los kleinianos y los winnicottianos se han unido para repudiar el trabajo de John Bowlby. Nunca ha existido un demonio como ése en el psicoanálisis británico, como la horrible teoría del apego. Conocí a John Bowlby bastante bien y era un buen hombre; en carne propia sufrió lo que es tener padres con un mal paternaje y fue criado por una niñera que después desapareció de su vida durante su infancia temprana. Así que conoció lo que es la separación desde muy pequeño y desde una experiencia personal, así que se propuso escribir al respecto.

Lo que John Bowlby estaba tratando de hacer era entender una experiencia devastadora, que sufrió personalmente, en términos de las mejores teorías científicas disponibles en su época, que eran la etología, y una teoría con la que él mismo se identificaba, que era una muy simple, y que sugiere que el infante humano nace en un estado de desprotección; porque todos nacemos... el problema real es el gran tamaño de nuestra cabeza, y que debemos salir del útero así, con la cabeza con un gran tamaño, por lo que somos vulnerables. Es un problema físico; Las cebras, por ejemplo, no tienen problemas. Así que necesitamos protección, y Bowlby pensó que el apego era un mecanismo evolutivo al servicio de la protección del infante humano. Si el infante se siente amenazado, buscará al objeto, es decir, que emitirá señales para que el objeto acuda por el llamado biológico de su cría.

Aquellos de ustedes que tienen hijos chicos, que lloran de noche, saben a lo que me refiero. Es algo que no se puede evitar. Personalmente, mis hijos, los dos tienen más de veinte, pero aún me afecta de la misma manera. "Uno es tan feliz como el menos feliz de nuestros hijos", como dice el dicho. Bueno, así que cuando estamos angustiados, buscamos a nuestra figura de apego. La mejor prueba, la mejor prueba del apego con la que me he topado es también un ejemplo ocurrido en mi familia: hace unos años, hubo un atentado terrorista en Londres, como ustedes saben. Un autobús explotó por una bomba. En ese entonces, mi hija tenía 15 años, y nunca me llamaba por teléfono aunque la vida de alguien dependiera de ello. Y llamarme desde el liceo, era más que humillante, el sólo considerar llamarme ya lo era. Y lo más que podía esperar de ella, como saludo en la tarde era: hola papá. Normalmente entraba como si nada a casa, sin decir nada.

Cuando la bomba explotó, ella de hecho intentó llamarme, pero yo no me enteré porque todas las hijas en Londres estaban tratando de llamar a sus padres y madres, y el sistema telefónico colapsó. Eso es apego, es la búsqueda de la figura de apego. Pero Bowlby estaba equivocado, puesto que esta conducta es de hecho común en todas las especies de primates, y algunas menos evolucionadas. Lo que el apego representa para homo sapiens como nosotros, es de hecho la creación de un mecanismo para transmitir transgeneracionalmente la subjetividad humana. La evolución dijo: ey, chicos, he aquí un mecanismo que puedo realmente usar para ayudarlos a aprender unos de los otros, y que puede ayudarlos a colaborar unos con los otros; voy a emplear la proximidad que el sistema de apego crea entre el cuidador y el infante para darle la oportunidad al cuidador de que le enseñe al infante sobre sus estados internos.

Tres son las capacidades transmitidas a través de esta vía, dentro del sistema de apego temprano: la primera es la capacidad de repre- 
sentar emociones, la segunda es el control de la atención, es decir, la capacidad de dirigir la consciencia de una cosa a otra, y de hecho, creemos que la consciencia humana está limitada por las experiencias que el cuidador es capaz de espejearle al infante. Sólo podemos ser conscientes de los estados internos cuyos equivalentes externos podemos hallar. Es el fundamento del proceso de construcción de consciencia.

Un trauma, por ejemplo, es traumático, no porque las vivencias de la persona traumatizada sean cualitativamente distintas a las que ustedes y yo tenemos, dado que las fantasías inconscientes, que se vuelven realidad en un trauma, son compartidas por todos nosotros, sino porque la mayoría de nosotros no ve reflejadas sus estados internos asociados dichas fantasías, reflejadas desde un referente externo. Lo que le da al trauma real es esa representación externa, que hace real algo que es interno, haciéndolo consciente, y generando un estado persecutorio en el individuo, aunque ese es tema aparte. Ese uno de los aspectos del sistema de apego.

Y la tercera es la capacidad reflectiva para mentalizar. Esta es realmente la función clave del apego, su logro más importante en términos de la mente humana. Y debido a esto es que la calidad de la relación de apego es predictora de las capacidades del individuo en todos los dominios mencionados. Así que si se tiene un apego seguro, también se tiene una mejor representación de las emociones, mecanismos atencionales más evolucionados, y mejores capacidades de mentalización.

Pero, ¿cómo sucede? Estoy seguro de que muchos de ustedes están familiarizados con esto: espejamiento materno contingente, sobre lo que hemos estado escribiendo muchos años. Es simple y realmente la experiencia con el otro, cuando uno se encuentra en el otro. Y es tan importante que si alguien no cuenta con un otro capaz de reflejar las intenciones de manera apropiada, entonces constantemente se generarán situaciones en las que esa persona esté buscándose a sí misma, tratando de entender qué es lo que necesita/ quiere.

De cierta manera, aunque mi madre era probablemente la madre más contingente, la que ponía más en práctica el espejamiento simulado, no era perfecta. Y había ocasiones que no espejeaba lo que me ocurría tan bien, y como consecuencia, yo tenía momentos de disociación, en los que sólo desaparecía. En los que dejaba de ser consciente de mis estados internos, dejaba de estar consciente. Esto tal vez no les ocurrió a ustedes, pero estoy convencido de que es una experiencia humana extendida. Y los niños víctimas de negligencia no tienen la oportunidad de sentirse espejados, comprendidos, lo que constituye un problema grave.

Esta es la diferencia entre una madre que no espeja y otra que sí lo hace. Acá puede verse que el espejamiento de una madre hacia su hijo tiene un efecto más calmógeno que el no espejamiento. Lo crucial del espejamiento consiste en que la madre se comunica con su infante de la siguiente manera: lo que ella demuestra en su rostro no es lo que la madre misma está sintiendo, sino lo que el infante está sintiendo. En eso consiste el arte de esto; y también en esto consiste el arte de la psicoterapia.

El espejamiento comienza con el acto comunicativo que consiste en transmitirle al otro que sabes cómo se está sintiendo, cargándole con el peso de saber que tú puedes saber cómo se siente; es un poco un arte, y no todos pueden hacerlo. Aquellos de ustedes que no puedan, retírense por favor.

Sabemos que el ser contingente al espejear es tan importante, porque en las situaciones experimentales del rostro de piedra que Ed Tronick creó, cuando la madre deja de interactuar con su infante, la búsqueda de éste por alguna respuesta de su madre se dispara dramáticamente, hasta que ella vuelve a interactuar. Así que ser capaz de verse a sí mismos en el afuera, es inmensamente importante para los infantes, puesto que les otorga un sentido de continuidad a su existencia, como les voy a mostrar en unos momentos. Estoy seguro que ustedes concuerdan conmigo.

Todo esto me lleva a la ciencia elevada. Sabemos que un niño que aprueba el test de la teoría de la mente en una edad más temprana, posee un estilo de apego más seguro. También sabemos que en las familias que se muestran juguetonas, los infantes pueden mentalizar más. Si puedes incursionar en un mundo que es serio, y al mismo tiempo no lo es, eso facilitará el desarrollo de la mentalización. También sabemos que este proceso lo media un neuropéptido denominado oxitocina. La oxitocina se encuentra presente en mujeres, sus hijos, también guarda un rol importante en el amamantamiento y numerosas situaciones rela- 
cionadas a infantes. Pero la oxitocina de hecho también está presente en los hombres, lo que resultó en un descubrimiento para mí. Resulta que al inhalar partículas de oxitocina durante un experimento, los hombres se mostraron menos hostiles durante el juego con sus infantes, es decir, jugaron mejor con ellos, debido al efecto de la oxitocina. Lo que es bueno, excepto para los infantes, que no se dejan engañar por un poco de oxitocina.

En este test, que consiste en decir qué es lo que está pasando por la mente de las personas que se muestran en las imágenes, y ahí está mostrándose la mente de la persona que están mirando, si se inhala la oxitocina con anticipación, el desempeño es mucho mejor, lo que es un descubrimiento importante, y el grado de mentalización es significativamente mayor. Todos nos volvemos un poco más mentalizadores con una pequeña cantidad de oxitocina. Necesitamos entender por qué sucede esto. Porque empezamos a ver esta parte de la cara (los ojos) con un poco de oxitocina. Estoy dudando en sugerir esto, pero la oxitocina, no es la panacea, pero la puedes conseguir en internet. Su limitación, su factor limitante es que tiene un periodo corto de duración, dura 45 minutos, 30 minutos. En nuestro laboratorio, es lo que asumimos, pero no voy a discutir el tiempo de vida de la oxitocina ahora.

El asunto es bastante simple; y voy a traer un ejemplo sencillo. Imaginen que están por tener una pelea con su pareja, sobre un tema crucial de índole doméstico, en el que ustedes necesitan sentirse comprendidos, y su voz escuchada. Les recomiendo que tomen la oxitocina y le digan a su pareja: querid@, ¿te importaría inhalar un poco de oxitocina? Ahora, mírame a los ojos; ¿qué hay acerca de las cosas para lavar? ¿por qué tengo que hacerlo yo cada noche? $\mathrm{O}$ algo parecido.

En mi laboratorio estamos llevando a cabo algunas investigaciones con oxitocina, y es de hecho bastante interesante. Yo mismo la he probado, pero el cambio no es dramático, no te pone drogado, no funciona así; no califica como un problema de abuso de sustancias.

Lo que es importante es que el apego y la oxitocina parecen estar relacionados. El ser humano es una de las especies que elige un compañero, copula con él, y se queda con él. Y cada vez que siente miedo, busca a este compañero y se quedan con él. Otras especies también muestran un comportamiento parecido, aunque el neuropéptido que está en juego es distinto.

La oxitocina entonces estimula el entendimiento de las demás personas, y está vinculada a la relación de apego, y es un poco como el viagra de la mentalización. Pero también es importante saber que demasiado apego tampoco ayuda a la mentalización. Estoy seguro que existe en español una frase que dice "love is blind" (el amor es ciego). Todavía no he encontrado un idioma que no tenga una frase que exprese eso, y seguro hay una razón para ello.

Resulta que cuando las personas tienen sentimientos intensificados, como cuando aman, su capacidad para mentalizar decrece dado que los centros cerebrales que revisamos antes, como las áreas pre.frontales y la unión temporo-frontales, responsables del proceso de mentalización, de hecho se desactivan, al tiempo que el apego se activa. Este estudio originalmente fue realizado por colegas de la University College London, que reclutaron a estudiantes de medicina, a los que les mostraron fotografías de sus parejas, a las que amaban, y compararon esto con fotografías de personas conocidas solamente. Encontraron que las mismas áreas cerebrales que se activan al ver al infante de uno, como el sistema límbico; constituyen un sistema de recompensa que alertan: "esa es la persona para mí, ese es mi bebe, ese es mi niño, ese es mi amor". Si se activa, hasta cierto punto impulsa la mentalización, pero pasado cierto límite, la inhibe. Es muy interesante el por qué sucede esto, aunque yo no esté complemente seguro de por qué. Pero existe un psicólogo, uno mejor que cualquiera de nosotros, que llegó a la siguiente conclusión. Una alta excitación emocional inhibe la mentalización, y ésta se torna no reflexiva, llena de asunciones equivocadas, lo que ayuda a explicar el resurgimiento de modos de pensamiento no mentalizadores.

Me gustaría usar a Shakespeare para ilustrar cuan mentalizador es. ¿Recuerdan ustedes a Otelo, la obra con un final triste? Primero que nada, Otelo demuestra cuán buen mentalizador es. Él se topa con un par de amigos que están peleando y exclama:

¿Qué es esto? ¿Cómo ha sido?

¿Nos hemos vuelto turcos, haciéndonos nosotros lo que el cielo impidió a los otomanos?

Por decencia cristiana, ¡basta de barbarie!

Está tratando de que entren en razón. Él es la misma persona que cuando su amor se ve prohibido, deja de mentalizar, deja de buscar 
alternativas en una situación, y atribuye la causa de la situación a una sola razón.

Por el cielo!, que he visto mi pañuelo en su mano.

¡Oh mujer perjura! Has endurecido mi corazón;

y me haces llamar a lo que tengo intención de hacer

un crimen, que creí un sacrificio.

He visto mi pañuelo...

Observa un objeto del mundo real y saca una conclusión. Tuvo un muy mal final, porque no era mentalización lo que estaba realizando, no consideró otras posibles alternativas. No mentalizó. Y la razón que lo explica es que al poner en práctica la mentalización, se activan el córtex prefrontal-lateral, y el córtex medio prefrontal, mientras que lo que pasó al observar a Cassio, fue que se activaron tanto su córtex temporal lateral, cortex prefrontal ventro-medial; Shakespeare no lo sabía, pero ustedes sí.

$Y$ considero que es sumamente importante que tengamos en mente que la comprensión psicológica puede derrumbarse en momentos de sobreexcitación, y entonces es rápidamente sustituida por confusión sobre los estados mentales internos durante dicha sobreexcitación. ¿Por qué es importante que lo sepamos? Porque los psicoterapeutas, de nuevo, nadie en esta sala, estoy completamente seguro de eso, pero sí hay psicoterapeutas allá afuera, que cuando el paciente sufre de alguna sobreexcitación, lo que intentan es hacer que entienda sus reacciones tan intensas, de reflexionar sobre las mismas, de implementar un poco de mentalización explícita, pero de hecho, el paciente no puede poner en práctica ninguna de estas alternativas. ¿Lo han notado? Lo que tienen que hacer ustedes es dejar de hablar, dar un paso atrás y esperar, porque nosotros mismos, en una situación de terapia, tenemos cierta excitación, estando con un paciente que muestra montos importantes de excitación, y lo que hacemos es tratar de regular su excitación de la manera que sabemos, por ejemplo, nombrando los sentimientos en juego, intentando que el paciente haga lo mismo; pero no funciona así. Vamos con lo que viene rápidamente.

Esto nos lleva al trauma, porque el trauma deja al niño en una situación en la que de manera crónica se encuentra expuesto a una sobreexcitación. Los niños víctimas de maltrato, particularmente en lo que se refiere al apego, experimentarán sentimientos de angustia y miedo, que disparan el sistema de apego, y por lo tanto, la búsqueda de proximidad, que en este caso deja al niño aún más expuesto a la situación que originalmente disparó la sobreexcitación. Y bien puede recordarle al niño la situación traumática, o lo deja en una situación de peligrosa cercanía con la persona que en realidad lo maltrata.

¿Cuántos de ustedes han atendido a niños víctimas de maltrato? ¿Víctimas de maltrato grave? Entonces, estarán de acuerdo conmigo en que en ocasiones uno trata de ser amable con ellos, y esto resulta contraproducente. Les hace peor en lugar de mejorarlos. Si uno trata de calmarlos, entonces explotan. Uno como psicoterapeuta dispara el sistema de apego y eso genera que en su mente, el niño se sienta expuesto a la situación de maltrato que le causa angustia y miedo, ante lo cual necesita de una figura de apego, lo que entonces se transforma e incrementa, en lugar de disminuir, en un conjunto de vulnerabilidades. Así que esa situación se repite en un ciclo que nunca termina, y que lleva a pique a la mentalización, por lo que ese niño no puede lidiar con uno como psicoterapeuta. Lo que necesitamos hacer es de nuevo aprender a dar un paso hacia atrás en esta situación.

Les doy un ejemplo clínico, de un paciente. Estoy tratando a un paciente con un trastorno de personalidad limítrofe. Esta persona, entra al consultorio. Ustedes probablemente la hayan visto también, porque ha consultado a un gran número de terapeutas. Es la misma persona de la que ya les hablaré, que en la segunda entrevista me dijo: "Dr. Fonagy, no sé si usted sabe cuán maravilloso es; he escuchado por otras personas que usted realmente entiende a personas como yo, pero nunca supe lo bien que se sentía eso." (mímica de numerosos besos y abrazos afectuosos). Bueno, unas semanas después, la misma paciente entra al consultorio y grita: "He estado viniendo por 8 semanas, ¿sabe? Y nada ha cambiado. ¡Nada ha cambiado! ¿Sabe lo que hace? ¿Tiene idea de lo que significa tener todos estos pensamientos y sentimientos suicidas, como los míos?. No, no lo sabe, ¿o sí? Esto es una pérdida total de tiempo, lo que usted hace. De hecho voy a denunciarlo al Instituto, porque estoy convencida de que lo que usted hace es francamente antiético." ¿Les suena familiar? Es probablemente la misma persona. 
Bueno, este soy yo en mi experiencia interna: "Me parece que usted está enojada". Y

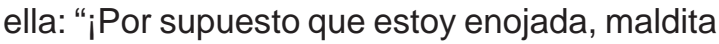
sea!, ¿Qué espera? ¿Qué saque un letrero que diga que usted es un mal terapeuta?". Y yo: "Me parece que usted está muy enojada". Y al final esto no lleva a ningún lugar bueno, porque ahí estaba yo, pidiéndole que reflexionara sobre ella misma, sobre cuán enojada se sentía, y esperando que así todo estuviera bien. Pero no lo estaba.

Según nuestro modelo, lo que ustedes tienen que ser capaces de decir es algo así como: "Mire, de verdad que me gustaría poder entenderla, realmente quiero poder escucharla, pero cuando alguien me está gritando, me resulta tremendamente difícil de entender o aún de escuchar." Ahora ven lo que quería transmitirles, ¿notan la diferencia entre los dos abordajes? Y así, me pongo a mí mismo ahí, y le pido al paciente que me mentalice un poco, "no puedes pensar en ti mismo solamente, piensa en mí". Esto es en parte como trabajamos nosotros.

Pero, ¿qué ocurrió entonces entre la segunda y la octava semana, o probablemente unas pocas más? ¿Qué pasó? ¿Qué salió mal? ¿Alguna vez han evaluado un paciente, que les parece la persona más mentalizadora, preocupada por lo que le ocurre a los demás que han conocido, por lo que ustedes quieren atenderla, una, dos, tres por semana? O diariamente, ¿por qué no? $Y$ después de unos meses de tratamiento, uno siente que el consultorio está siendo abatido por una bomba atómica. ¿Les ha pasado esto? ¿Si? ¿Por qué creen que es esto? Lo único que pasó fue que una relación de apego se creó entre ustedes y el paciente, y para este tipo de pacientes, cuando se crea un vínculo de apego, entran entonces en este ciclo en el que se hiperactiva su sistema de apego y entonces desciende su nivel de mentalización. Y lo que ustedes deben aprender a hacer, es a lidiar con esto, tratando de calmarlos, por ejemplo, bajando la voz, no diciéndole por ejemplo: "Querida, pareces muy molesta", lo que elevaría la activación del sistema de apego, sino aprender a dar un paso hacia atrás, y de hecho demandar una relación más mentalizadora.

¿Cómo vamos de tiempo? ¿Bien? ¿Están bien? Puedo parar en cualquier momento para responder sus preguntas, por ejemplo. Quisiera hablar un poco sobre la no mentalización, para darles la sensación de que... porque la clave para un proceso terapéutico exitoso, y esto es probablemente la única cosa que deben aprender a hacer, es a identificar cuando el paciente ha dejado de mentalizar. Ahora, ¿cómo sé cuando un paciente dejó de hacerlo? Hay tres pistas: la primera, el paciente empieza a pensar en un modo que Mary Target y yo denominamos "modo equivalente al psíquico". No es muy complicado, y sí muy fácil de reconocer. Las personas que presentan este modo creen que todo lo que piensan, todo lo que está en su mente, es real. Su mundo interno guarda de hecho una correspondencia con la realidad exterior. $Y$ en ese punto, cualquier vivencia psicológica puede resultar absolutamente terrorífica. Algo como una fantasía, o la proyección de la misma se vive como terriblemente real. Por otro lado, no hay manera de que su forma de pensar sea distinta a la suya. "Sé cuál es la situación, y la situación es ésa. Nadie puede decirme lo contrario".

Antes de que perdamos el sentimiento de simpatía por la persona, necesitamos intentar imaginar cómo es que los malos sentimientos acerca de uno mismo sean reales. No sé si les pasa a ustedes, pero a veces me siento como esta mañana, que me levanté después de haber viajado, y uno sabe cómo se ve, bueno, cómo me veo yo, y fui al baño y me dije a mí mismo: "Dios mío, te ves horrible". Eso resultó positivo, me ayudó. Y pensé que era algo pasajero, que era sólo un pensamiento. Pero imagínense si yo pensara que eso era cierto, que yo realmente soy feo. Bueno, lo soy, pero me pongo en una ubicación más allá de eso, en un modo mentalizador. Piensen en cuando se han sentido avergonzados, e imaginen lo que es vivir esa experiencia vergonzosa en un equivalente psíquico de vergüenza total; es algo que te destruye desde adentro. Y eso es realmente lo que estos pacientes experimentan funcionando en este modo de pensamiento de "equivalente psíquico". Es increíblemente doloroso. Y para nosotros resulta difícil empatizar con ellos, me parece, debido al nivel de angustia que experimentan.

Como alternativa a lo antes expuesto, tenemos el modo "como si", que es mucho más difícil de detectar; no existe conexión entre la realidad física y la mental. La realidad mental puede guiarse de manera independiente a lo que está sucediendo en la realidad. Freud describió esto como un dominio que la persona mantiene separado del mundo real externo, libre de las 
exigencias de la vida, como si fuera una reserva. George Steiner escribió sobre esto. Pero, de nuevo, probablemente nadie en esta sala, pero algunos de nosotros tenemos pacientes que cuando nosotros estamos hablando sobre todas las cosas que debemos hablar: sobre que se sienten enojados o tristes, desilusionados o rechazados, frustrados, sobrepasados. Y tocamos todos los sentimientos y todas las posibles razones para los mismos, y somos muy buenos hablando sobre eso, y el paciente escucha nuestras interpretaciones. Pero nada cambia; ¿se han dado cuenta de eso? Tal vez eso no les pase a ustedes. Tal vez en Uruguay eso no sucede. Pero en Londres sí, y eso es lo que yo llamo modo "como si". Las cosas sobre las que el paciente habla dejan de parecerle reales.

La experiencia interna a la que nosotros como terapeutas nos dirigimos, no tiene un punto de agarre, es como una rueda interna que gira constantemente, y puede hacerlos sentir terriblemente mal. Les puede hacer sentir vacíos, sin un sentido, horriblemente.

Un tercer tipo de pérdida de mentalización es el modo teleológico y también pasa con niños chicos, e implica que las cosas tienen que suceder en el mundo físico para que la persona las sienta como reales. $Y$ esto se ve cuando el paciente llega y, no sé, le pide al terapeuta que le firme una carta. Ignoro si ocurre acá, pero en Inglaterra a veces recibimos pacientes de tal forma que éstos puedan acceder a una asignación de los servicios sociales, si uno les firma una carta diciendo que la persona tiene un trastorno. ¿Es lo mismo acá?. Bueno, el paciente entra el consultorio con un papel en la mano, y dice: "antes de que diga nada, quiero que firme esta carta". Yo le respondo: "me gustaría pensarlo antes, ¿de qué se trata la carta?", a lo que el paciente replica: "No lo piense, sólo fírmela, ¿por qué? Sólo fírmela, no es complicado. Acá tiene una lapicera, sólo fírmela." Y yo le digo: "Creo que deberíamos hablar un poco antes de firmarla". Y el paciente exclama: “¿De verdad?" Le estoy pidiendo algo muy sencillo, que firme la estúpida carta".

¿Han lidiado con eso? Hasta que uno de hecho la firma... tiene que suceder en el mundo real para que la persona sienta que a uno le importa, y uno les devuelve lo que pasa diciendo: "creo que usted quiere que yo firme esta carta para sentir que me importa, justo antes de que me vaya de licencia o de viaje". Y el paciente responde: "Eso es una estupidez, un insulto a mis intenciones. Sólo firme la carta". Bueno, el punto es que los pacientes así nos hacen hacer cosas de tal forma que dichas acciones expresen estados subjetivos que no pueden crear en sus mentes como resultado de lo que uno tiene en la propia, por lo que nos hacen hacer cosas. $Y$ a veces eso no es suficiente; tiene que ser el sistema hospitalario en su totalidad el que lo haga, corriendo alrededor en círculos, como gallinas degolladas, entre que el personal decide si admitir a esta persona o no, aparte de lo que generan pacientes así, como la creencia de que son manipuladores, etc.

Tuve una vez una paciente que estaba arriba de unas escaleras, y que a propósito se tiró para romperse un hueso. Normalmente, la gente decía que era manipuladora, y que hacía este tipo de cosas para llamar la atención. Sí llamó mucho la atención, pero existen muchas y más sencillas maneras en las que podía haberla obtenido. Ella tenía que hacerse sentir que las personas se preocupaban por ella y lo que le hacía creer que la gente realmente se preocupaba por ella era tener al personal del hospital en la emergencia poniendo sus huesos en su lugar. Eso le hacía sentir que a la gente le importaba, y de otra manera no podía sentirlo. $Y$ eso es algo que nos resulta a nosotros muy difícil de detectar.

Bueno, ahora déjenme mostrarles una secuencia en la que esto puede suceder; puede que se presente así o no. La persona experimenta un sentimiento de perturbación, una pérdida que dispara su búsqueda de apego. Esta perturbación puede ser de distintos tipos, por ejemplo, sus amigos le dicen que ya no quieren continuar la amistad con él/ella, podría ser el hecho de que ustedes, como terapeutas, estén unos días de licencia; esto incrementa su necesidad de apego, dispara su sistema de apego, los lleva a ese círculo del que hemos estado hablando. A su vez, esto conlleva a un fallo en la mentalización, lo que los deja en un modo de equivalencia psíquica, aumenta la experiencia de tristeza a un nivel insoportable, con el que no pueden lidiar. Esto los lleva a su vez al modo "como si", donde disocian, empiezan a hipermentalizar; sienten que son insignificantes, sin valor, vacíos. Y ahí, algo real tiene que ocurrir, algo que se presenta como una solución física a su problema o a la crisis que les genera no sentirse más como agentes activos de sus vidas. 
Y es en ese momento cuando ustedes están en riesgo de que ese paciente haga algo, como autolesionarse o tener conductas suicidas. Me parece que ya he descripto la situación. Quizás debería parar para que hagan preguntas, ¿les parece bien? ¿No? Bueno, entonces voy a seguir un poco más. Siempre hago lo que Ricardo dice que haga.

Bueno, déjenme entonces decirles brevemente lo que hacemos al respecto. Voy a presentarles brevemente lo que hacemos en intervenciones basadas en la mentalización. Déjenme contarles rápidamente lo que hacemos, para que tengan una idea de nuestra técnica. Porque nuestra técnica... hasta ahora lo que saben es que nuestra teoría es psicoanalítica, pero nuestra técnica no. Porque la idea simple que está detrás del tratamiento basado en la mentalización es la asunción de que nuestro paciente con trastorno limítrofe de la personalidad presenta una falla temporal en la mentalización. No siempre, pero es vulnerable a perder la capacidad para mentalizar. $Y$ en ese momento, su subjetividad colapsa, experimentan un dolor psíquico terrible, su vivencia de emociones negativas se amplifica masivamente, poseen una sensación de descontrol cognitivo, y lo que intentamos hacer como psicoterapeutas es, con mucha delicadeza, y tanto como podamos, expandir y clarificar sus representaciones de estados mentales. Y eso es todo. No intentamos ayudarlos a tener una mejor capacidad de insight, no intentamos contactarlos con recuerdos reprimidos, no intentamos reestructurar su mundo mental o cogniciones, no les señalamos sus fallas para pensar racionalmente. Simplemente intentamos entender sus estados internos, para ayudarlos a mentalizar la situación en que se encuentran. ¿Cómo lo hacemos?

Empleando intervenciones simples: nos enfocamos en las emociones. Nos centramos en el amor, el odio, el deseo, entusiasmo o catástrofe. Nos centramos en sus mentes, y no en su conducta. Eso es en extremo difícil, porque muchos otros terapeutas tratan de hacer algo sobre cómo actúa el paciente, y lo que nosotros intentamos todo el tiempo es entender cómo se siente, qué pasa por sus cabezas, qué se les cruzaba por la mente antes.

Nos apegamos a las personas implicadas en las situaciones, nos enfocamos y cito "en la transferencia" y en el aquí y ahora, y empleamos nuestras propias mentes como modelo para el paciente, y decimos cosas como: "eso es realmente llamativo, porque en la situación que usted describió, yo me hubiera sentido así, pero parece que usted se siente de esta otra manera. ¿Cómo puede ser?".

Esto no es abrirse con el paciente, sino que genuinamente tratamos de ver cómo nos sentiríamos en una situación así. Pero la parte más importante de la técnica es identificar la no mentalización en el paciente. Estamos convencidos, y éste es probablemente el segundo punto que me gustaría destacar, de que en ocasiones podemos causarles daño a estos pacientes durante la intervención psicológica. Podemos causarles daño cuando erramos al no identificar los momentos en los cuales no pueden mentalizar. $Y$ no los ayudamos a recuperarse, y mientras tanto, su capacidad de mentalizar se va perdiendo aún más. Y lo que puede suceder en ocasiones así, es que el tratamiento se prolongue por años puesto que el paciente se torna dependiente del terapeuta como la persona que lo ayuda a mentalizar. $Y$ nunca adquieren la capacidad, porque el terapeuta tampoco nunca identificó que el paciente no la poseía en primera instancia. El terapeuta siempre asumió que el paciente la tenía. Así que los pacientes asisten a consulta semana tras semana, a veces año tras año esperando que a través del terapeuta puedan adquirir esta capacidad tan preciada. Pero el terapeuta siempre ha sido demasiado complicado para ellos, siempre se ha comportado como una persona intentando enseñarle a un niño de 6 años la teoría de la relatividad. No es algo bueno.

Y ¿qué hacemos? Esto es lo que de hecho funciona en el campo práctico: centrarse en las fallas de la mentalización, si han dejado de mentalizar, o si funcionan en un modo psíquico equivalente, o en el modo "como si", o en el modo teleológico. Y entonces como terapeutas deben hacer algo que en muy pocas ocasiones hacen los psicoanalistas: detener al paciente $(y$ muestra una mano en señal de pare). Esta es la mano de la mentalización. Y si están desesperados, levanten ambas manos en señal de pare. El principio de intervención es el siguiente: no deben dejar que la no mentalización tenga lugar en el consultorio, con ustedes como terapeutas presentes.

Se trata de identificar, y después de ir hacia atrás hasta la última parte de lo que estaba narrando el paciente que sí comprendieron, y en la que el paciente estaba empleando la 
mentalización. Normalmente, en el consultorio lo que se tiene es un episodio que el paciente está relatando, y en el que la mentalización no fue utilizada, y el terapeuta, automáticamente, como el reflejo al golpear la rodilla, intenta que el paciente reflexione al respecto. Pero eso no es posible. Si la persona no está mentalizando, uno no puede hacer que reflexione acerca de lo que pasó, no podemos preguntarle: “¿por qué le parece que se siente tan descontroladamente enojado?". No funciona. "Parece furioso, me pregunto por qué". Tampoco funciona. Lo que sí funciona es: "Bien, usted comenzó a gritar, ¿qué estaba pensando antes de comenzar a gritar?". Porque usted estaba hablando de lo que había ocurrido entre usted y su jefe, y me pareció que usted se sintió de X manera, pero entonces comenzó a gritar. Cuénteme un poco más acerca de lo que ocurrió entre usted y su jefe.

¿Lo ven? Retrocedemos hasta el último momento antes de la falla en la mentalización. Y ustedes como terapeutas pueden analizar esa situación, porque se asume que hubo algo en eso que ocurrió que disparó la falla en la mentalización. Así que si con el paciente podemos explorar eso con mayor profundidad, eso le resultará benéfico, y la próxima vez existe la posibilidad de que suceda un poco menos.

La razón por la que más probablemente la mentalización haya dejado de tener lugar con ustedes como terapeutas en el consultorio, desafortunadamente es que ustedes hayan hecho o dejado de hacer algo. Así que algo que generalmente hacemos en las intervenciones basadas en la mentalización es algo que nunca haríamos como psicoanalistas; es más, es algo que me prohibieron hacer, y eso es decir: "lo siento". Y ahora, con este tipo de pacientes, lo digo muy a menudo. Les digo que siento mucho no haber entendido a dónde querían llegar. Les digo: "Estoy lento. Tal vez hoy estoy teniendo uno de esos días difíciles en los que no estoy entendiendo, y cometí un error". Así tomo responsabilidad por cualquier sensación de angustia generada en el consultorio. No le tiro la pelota al paciente para que reflexione al respecto, sino que me lo apropio como algo que bien pude haber generado yo.

También intentamos mentalizar la relación terapéutica, muy paulatinamente. Así que trabajamos la transferencia, pero no con insights muy profundos, sino con pequeños pensamientos y sentimientos. Muy gentil y livianamente. No cosas inconscientes y profundas, sino los pensamientos y sentimientos cotidianos. Por ejemplo, le podemos decir: "Es muy extraño, porque cuando usted entró, me dio la impresión que le dio gusto verme. Pero ahora está sentado ahí mirándome como mi perro. No es un insulto, quiero mucho a mi perro, pero a veces me mira y me hace sentir culpable. ¿Qué pasó? ¿Qué pasó entre nosotros? ¿De qué me perdí?". Y ya está, con eso basta. Lo que tratamos de hacer es ayudar a recuperar la mentalización. No tratamos de hacerlos entender toda una filosofía; somos modestos en nuestros objetivos.

El objetivo de ustedes debe ser ayudar al paciente a aprender acerca de la complejidad de sus pensamientos y sentimientos, acerca de sí mismo, y de otros. Y sobre cómo estos pensamientos y sentimientos llevan a acciones.

Un último punto sobre lo que, según nuestro modelo, no se debe hacer: no se debe asumir que uno es el experto. No estamos ahí para decirle al paciente lo que está pensando, o lo que está sintiendo, o cómo debería comportarse, o cuáles pueden ser las razones que subyacen a su forma de pensar, o de lo que son conscientes o inconscientes. De nuevo, estoy seguro que ninguno de ustedes, pero allá afuera hay ciertos terapeutas que dicen cosas como: "Lo que creo que usted está realmente diciendo es..." ¿Saben a qué me refiero? O dicen: "Lo que creo que está detrás de todo esto que usted está comentando", como si los terapeutas supieran lo que pasa por la mente de los pacientes. Esto resulta muy tóxico para estos pacientes, porque ellos mismos desconocen lo que les pasa por la mente. Está bien para ustedes si sus analistas les ayudan a tener un insight sobre lo que les sucede, pero estos pacientes tienen primero que descubrir lo que les ocurre psíquicamente; no se les puede decir lo que les pasa.

Así que la postura que recomendamos es la del ignorante, la de la curiosidad acerca de lo que está ocurriendo. Un cuestionarse constantemente sobre lo que está sucediendo en la mente del paciente; mantener una postura curiosa. Y tratar más bien no de sentarse de frente al paciente -y no lo digo con un sentido teleológico, sino metafórico- diciéndole al paciente cómo se siente, sino de sentarse a su lado, y junto con el paciente, tratar de pensar acerca de lo que está sucediendo en esa situación. Es un abordaje colaborativo, no uno de experticia.

Bueno, hasta acá llegamos por hoy. 
Algunas precisiones acerca del tema realizadas a partir de preguntas del público asistente

¿Por qué utilizar en la definición de mentalización la expresión "imaginación" y no "percepción"? ¿Sería mejor decir percepción? ¿O se trata más que nada de una elaboración imaginativa intelectual, una simbolización? Es decir, ¿cuánto hay de percepción de la experiencia directa, o por empatía, y cuánto hay de elaboración mental o imaginación?

Peter Fonagy.: Bueno, empleamos la palabra imaginación, como parte de la definición por una razón muy simple, y ésta es que creemos que llevamos a cabo un acto imaginativo para entender lo que otra persona está pensando o sintiendo. Evidentemente es sólo una de muchas dimensiones, de las cuales no hemos hablado todavía, que la mentalización toca.

Uno puede mentalizar si se centra en el exterior, por ejemplo, en el rostro de una persona, como vimos en las fotografías anteriores, cuando los estados mentales de esa persona pueden ser más o menos percibidos. O uno puede mentalizar llendo un poco más allá de lo que es obvio de manera inmediata, y calcular lo que la persona está sintiendo o pensando. Dicha habilidad requiere de la imaginación. Resulta que tanto la mentalización centrada en el exterior como la centrada en el interior están mediadas por partes del cerebro ligeramente distintas. Y también resulta que ambas necesitan estar en equilibrio para mentalizar apropiadamente. Y cuando uno está demasiado centrado en el exterior o en el interior, la mentalización falla.

Por ejemplo, los pacientes con trastorno limítrofe de la personalidad tienen la tendencia a enfocarse en lo exterior al momento de mentalizar, tanto que a veces saben mejor que uno cómo nos sentimos. Así que te dicen: "me parece que te sientes un poco cansado". Y uno de verdad está un poco cansado, así que nos sentimos impresionados por lo conectados que estos pacientes están con nosotros. Pero al mismo tiempo, ellos no son capaces de sacar conclusiones acertadas en términos de los estados internos; por ejemplo, sobre por qué puede uno sentirse un poco cansado, qué significa para uno estar un poco cansado, o darse cuenta de que uno está cansado y sin embargo está ahí atendiéndolos. Pueden simplemente decir: "Usted está cansado y no quiere verme".
Eso es un fallo en la imaginación. No pueden decirse a sí mismos: El terapeuta está cansado y ¿no es fantástico que aunque parece cansado, y probablemente se sienta un poco cansado, está ahí, aunque son las 7 de la tarde?". No, lo más importante en la mente del paciente es que el terapeuta debería dormir. Así que el paciente no puede enfocarse en los estados internos para mentalizar, puesto que están en extremo dominados por el enfoque externo.

Un ejemplo mucho más sencillo de esto, y estoy seguro que les ha ocurrido a ustedes. El paciente exclama: "Miró su reloj, ¡lo vi mirando su reloj! Está harto y quiere que me vaya, ¿no es así?". Y uno le dice: "No, no, no. Por supuesto que no. Sólo estaba mirando cuánto tiempo nos queda juntos". Y el paciente refuta: "Y ahora ¡está mintiendo!". Lo cual es cierto. Pero era una falla en la imaginación el hecho de que el paciente no pueda contemplar que uno esté mirando el reloj por cualquier otra razón que no fuera deshacernos de él. Esa es la dimensión de estar más enfocado en lo externo o en lo interno al momento de mentalizar.

¿Cómo graduar la activación del apego como para disparar el proceso de mentalización pero sin inhibirlo?

Bueno... esa es la razón por la cual la psicoterapia es un arte más que una ciencia. Así que, arte o ciencia. Es realmente importante que como terapeutas creemos una relación de apego con nuestros pacientes, porque a menos que exista un vínculo de apego no va a ser posible que ellos descubran sus mentes a través de las nuestras. ¿Entienden a lo que me refiero? Están programados, como todos nosotros, para descubrir sus mentes a través de la mente de las personas con las que estamos apegados. Pero si activamos su sistema demasiado, no pueden pensar, no pueden descubrir nada, además del hecho de que su terapeuta no sirve. En eso consiste el arte, en balancear ambos factores, en juzgar adecuadamente la distancia. Cuando estamos durante la formación de terapeutas, una de las cosas que intentamos enseñarles es a manejar esa situación. Ser capaces de acercarse pero estar preparados para retroceder, y no quedarse pegados a ellos demasiado. No hay una fórmula simple para eso, excepto observando esa capacidad de absorber lo que se está diciendo. 


\section{¿Le parece que este método es aplicable en un tratamiento breve?}

Acabamos de desarrollar, yo no, Alessandra Lemma, Mary Target y yo desarrollamos una intervención breve denominada DIT, el nombre es muy corto, DIT, que significa Terapia Dinámica Interpersonal (DIT son las siglas en inglés).

Les voy a dar un consejo. Si alguna vez desarrollan un tipo de intervención, hagan que sus siglas sean 3 letras; si son 4, no va a funcionar. Ya saben, la CBT (Terapia Cognitivo Conductual), la TFB (Terapia Enfocada en la Transferencia) funciona, la MBT funciona (Terapia Basada en la Mentalización), la CAT (Terapia Analítica Cognitiva, funciona. Las terapias abreviadas en 4 letras no funcionan. Así que la DIT, 3 letras -funciona-; recién publicamos un libro llamado así "Dynamic Interpersonal Therapy", y manual, es para tratar la depresión. Es difícil emplear técnicas de mentalización con personas deprimidas. Si me preguntan a mí, los tratamientos breves con personas con trastorno limítrofe de la personalidad son dañinos, por lo que si no tuviera un mínimo de un año para tratar a un paciente así, preferiría no tratarlo, que tratarlo por menos tiempo. Eso si me preguntan a mí.

Existe evidencia de que la terapia cognitivo conductual, en un periodo de 16 sesiones, los empeora. Los pacientes están peor que si no los hubieran tratado. Pero ustedes pueden decirme que el seguro de salud solamente cubre 20 sesiones; ¿qué puedo decir?: "¡No tomen ese dinero sucio!". No sé qué decir en ese punto.

Puedo decir, por experiencia propia, que en nuestros estudios con dos grupos con asignación aleatoria, y recientemente terminamos el tercero de ellos, con adolescentes, no encontramos diferencias entre el grupo control y el que recibió tratamiento en un lapso de 6 meses. Así que es recién después de los 6 meses que empezamos a ver diferencias entre los grupos. Sólo estoy siendo honesto.

Vimos a los pacientes una vez por semana de manera individual, y una vez por semana de manera grupal. Ambos tipos de terapia simultáneamente. Al principio, los pacientes afirman que los grupos son una pérdida de tiempo, que no quieren asistir. Sólo quieren ir a la terapia individual. Y nosotros les decimos que esas no son las reglas con las que jugamos. Que el trato es que vayan a ambos tipos de terapia. Al final de los 18 meses de tratamiento, dicen que lo único que les sirvió fue la terapia grupal, que la individual resultó una pérdida total de tiempo.
No creo ninguna de las dos afirmaciones, pero es cierto, al manejar estos grupos, que uno ve a los pacientes siendo capaces de hablar unos con otros acerca de la mentalización mucho mejor que lo que los terapeutas pueden hacerlo.

$Y$ con los adolescentes lo que hacemos es que los vemos individualmente una vez a la semana y una vez al mes por ahora, aunque realmente nos gustaría hacerlo dos veces, en una sesión de terapia familiar para trabajar la mentalización basada en contextos familiares. Por ahora, en ninguno de los dos casos que expuse se trata de intervenciones breves.

Si alguno de ustedes inventa una intervención breve basada en la mentalización, avísenme. Clamaré que fue mi invento, pero... lo único que hacemos de manera breve es un tipo de programa educacional que nos ha resultado muy útil para antes de comenzar la intervención terapéutica. Seguimos un protocolo para enseñarles a los pacientes acerca de la mentalización; es como un grupo psicoeducativo. Porque al principio los pacientes llegan y dicen: ¿Qué demonios es eso? Yo puedo hacerlo, puedo hacerlo con los ojos cerrados, puedo hacerlo incluso mejor que usted. Y nosotros les decimos: "está bien, pero venga al grupo psicoaeducativo para entender lo que para nosotros significa mentalizar. Tal vez no tenemos la misma idea".

$Y$ a los pacientes no les gusta el grupo, pero hemos logrado reducir el número de deserciones al tener un grupo psicoeducativo al principio, para reducir el número de deserciones.

Realizamos una sesión de intervención familiar con MBT-FT, que solía ser el SMART, pero esas son terapias breves. Se basan en la idea de que interviniendo en el sistema familiar, se puede impulsar la mentalización en toda la familia. Y no se espera que los cambios ocurran en el niño o la familia por separado y de manera rápida, sino que el cambio se dé en el sistema completo y que sea el sistema el que sostenga mejor la mentalización dentro del mismo. Es similar a una intervención psicoeducativa, en cuanto a que se intenta que la familia completa adquiera una forma de pensar similar.

A veces cuando se enfoca en particular el tema de la mentalización (que me parece imprescindible en el tratamiento con pacientes, como usted ha planteado, y me parece de buen clínico esa postura), es que a veces se dejan de lado otros aspectos también centrales en el encuentro, como por ejemplo la 
seducción que parece evidente en el ejemplo del vaso de agua.

Estoy totalmente de acuerdo con lo que usted dijo. En términos de la riqueza de las relaciones humanas que usted mencionó, cualquier vínculo tiene varios aspectos. Además de yo sentirme comprendido cuando tenía sed y tenía deseos de tomar agua, también existió una sensación de sentirme nutrido por la atención. Ella me hizo sentir que alguien estaba pendiente de mí, que alguien quería ser bueno conmigo. A medida que trabajamos con pacientes, aún con los que son portadores de trastorno limítrofe de la personalidad, parte de nuestro trabajo con la mentalización consiste en que adquieran la noción de que la motivación humana es multicausal. Y lo hacemos todo el tiempo como terapeutas, cuando por ejemplo destacamos cómo nuestra perspectiva es distinta de la de ellos, o cómo nuestro entendimiento de algo es diferente del de ellos. Hacemos esto, pero en este tipo de intervenciones, probablemente la pequeña diferencia en el énfasis sea que lo ponemos en el punto de vista fenomenológico. Voy a comentar, por ejemplo, sobre el aspecto seductor que usted mencionó, bueno, no estoy seguro respecto a eso, pero ella quería demostrar que podía y quería hacerme sentir atendido. Lo que haría yo si ella fuera la paciente, sería decirle algo así como: "Es muy interesante, ¿sabe? Usted me dio el vaso con agua y yo de hecho sentí que alguien se preocupaba por mí. ¿Esa era su intención? ¿Estaba pensando usted en eso o simplemente sucedió? Es muy curioso, porque fue así como me sentí". Y mi propósito al plantear las cosas así no es que ella se dé cuenta de su impulso por hacer sentir a otras personas cuidadas, sino que sea consciente de la riqueza del sistema motivacional humano y que ella misma tiene muchas razones para hacer estas cosas. ¿Notan la ligera diferencia en el énfasis que ponemos ahí?

Me gustaría discutir un poco más. La TBM (Terapia Basada en la Mentalización), tres letras, ¿vieron?, no es una terapia orientada a promover el insight en los pacientes, sino que intentamos que recuperen su capacidad para mentalizar. Ahora, comúnmente, después de eso, los pacientes quieren dar ese siguiente paso hacia el insight, lo demandan; desean hacer un proceso de terapia orientado al insight, pero eso ya no es lo que llamamos TBM. Nadie está diciendo que la TBM es la única terapia que funciona, la única buena, nada de eso. Es una técnica, no una escuela. Es una técnica encaminada a ayudar a los pacientes a superar un circulo vicioso que impide que exista un vínculo terapéutico productivo con un paciente altamente problemático. Es todo, no aspiramos a nada más.

También mencioné muy al principio, que uno de los aspectos más saludables del vínculo terapéutico es el fallo en la empatía. En otras palabras, una ruptura en la alianza terapéutica, porque así se crea una necesidad imperante en la persona, por tratar de entender cómo sucedió eso. Y me parece que lo mismo sucede con los infantes. El sistema es de hecho bastante robusto, es decir, no requiere que exista una persona que espejee apropiadamente todo el tiempo, y probablemente, como se mencionó acá, es positivo que no suceda así. Me gustaría agregar algo que mi amigo George Gergely me puntualizó, y es que el punto crítico no consiste tanto en la presencia del espejamiento, sino la expectativa por parte del niño de que lo van a espejear. La decepción que conlleva dicha expectativa es lo crítico.

Así que si confías en que alguien te va a espejear, y de repente eso desaparece en un modo que ustedes no habían podido predecir, eso es lo que desorganiza al apego. $Y$ eso es de hecho lo que las investigaciones de LyonRuth muestran, que lo que es realmente tóxico es cuando la madre repentinamente no muestra ninguna emoción al interactuar con su hijo.

Relacionado con esto que está diciendo nos preguntamos si la mentalización facilita el levantamiento de la represión o la integración de partes clivadas, escindidas, por ejemplo en los pacientes border.

La respuesta a eso sería sí, porque facilita el desarrollo de mecanismos atencionales, que son necesarios para reprimir. $Y$ de hecho existe buena evidencia al respecto.

Usted hizo referencia a que en ciertas situaciones había una sobreactivación del sistema de apego, por ejemplo en las situaciones de violencia temprana cuando la figura de apego ejerció violencia sobre el individuo y eso deja una marca indeleble. Le quería preguntar si ésa es la única situación que puede generar la sobreactivación del sistema de apego.

Es una pregunta maravillosa, porque no sabemos con certeza; sabemos que el sistema 
de apego puede... el apego funciona como un círculo, que normalmente acaba por sí mismo. Así que se activa, con una intencionalidad de fondo, por alguien que lo regula y así se cierra el ciclo. $Y$ es un sistema hermoso cuando uno lo ve en funcionamiento con infantes. Muy hermoso. Pero no así cuando el ciclo no se cierra, por ejemplo, con el trauma. Entonces se activa pero luego no logra desactivarse y a eso me refería yo con la situaciones de violencia. El niño queda atrapado en su necesidad insatisfecha de seguridad y protección. No la puede resolver y por eso se vuelve traumática.

Por ejemplo, estoy seguro de que ustedes tienen pacientes que buscan parejas similares a figuras de su pasado. Por ejemplo, mujeres que han sido víctimas de abuso se ponen a sí mismas en situaciones de altísimo riesgo personal, y da la impresión que en parte lo hacen para intentar satisfacer algún tipo de necesidad de apego que quedo insatisfecha. $\mathrm{O}$ adolescentes mujeres que quedan embarazadas, para así lidiar con el apego. Esos son reactivaciones del sistema de apego, causadas por un cúmulo de razones. Una de las cuales es claramente un trauma, pero aunque lo crean o no, existen probablemente docenas de causas que pueden llevarnos al mismo lugar. En mi caso particular siento, por experiencia propia, que más importante que el trauma es la negligencia, la negligencia temprana, que deja a las personas que lo sufrieron en una situación de incapacidad para crear vínculos de apego que les servirían para que sus funciones evolucionaran.

Así que niños víctimas de negligencia temprana se comportan de una manera, estoy hablando de niños pequeños, que daña las relaciones de apego. Así que el mismo contexto que está ahí para ayudarlos a lidiar con los problemas que les ocurren internamente, es el contexto al que ellos dañan. $Y$ eso no ocurre porque hayan sido víctimas de relaciones abusivas, sino que todo eso puede haber sido iniciado por una situación de negligencia, que posteriormente desorganiza todas las relaciones de apego, y se genera un efecto en cascada que degenera en todos los problemas que desarrollan después.

Creo que es una pregunta maravillosa la que usted hizo, porque no se puede detener el reloj. Esto es un continuum. El desarrollo del niño es algo que ocurre de manera prolongada. Y si algo salió mal en el comienzo, al principio, los genes, el nivel de estrés de la madre durante el embarazo y la vida intrauterina del bebe, entonces el niño estará bajo mayores factores de riesgo. La relación original a partir de la cual debería desarrollarse un sistema de apego apropiado, deja al niño en una situación de negligencia afectiva.

El tema del apego en la relación pacienteterapeuta es equiparable o se puede relacionar con el concepto de transferencia, o ¿cómo piensa usted la relación transferencial paciente-terapeuta?

Esa es una pregunta más fácil. Yo podría... si yo fuera una persona grosera, que no soy, sino que soy muy amable, como se nota, podría decirle: "¿Podría ayudarme definiendo lo que es la transferencia?". Y entonces podríamos empezar a hablar sobre el tema, siempre y cuando coincidamos en lo que consideramos transferencia; es un término que creamos, pero parece que fuera algo existente por sí sólo allá afuera. Y así fuera no existe manera de vincular apego y transferencia, porque la transferencia existiría por sí misma, no estaría ligada a nada.

Existe un estudio reciente sobre precisamente este tema. El único estudio controlado que conozco, en el que capacitaban al mismo terapeuta para hacer interpretaciones sobre la transferencia y para no hacerlas, mostró que no había diferencias significativas respecto a los resultados de la terapia, excepto para aquellos individuos que tenían relaciones objetales pobres previas al inicio de la intervención. Esos individuos se desempeñaron mucho mejor en contextos en donde abundaban las interpretaciones sobre la transferencia. Mi opinión al respecto es que si se tienen individuos con relaciones objetales pobres, y una capacidad para mentalizar pobre, y que por lo tanto presentan constantes dificultades de relacionamiento con el terapeuta, y dichos pacientes tienen un terapeuta que no habla de su vínculo con ellos, entonces todo se cae. Necesitan un terapeuta centrado en la transferencia que considerará como parte importante del análisis, como decimos en el psicoanálisis, aspectos de la relación con esa persona. Porque el manual dice que así debe ser. Pero si el manual dice lo contrario, entonces el vínculo paciente-terapeuta se ve en problemas. Me parece que la diferencia que ese estudio observó tiene dos causas. Por un lado, estos individuos se beneficiaban de un abordaje en el que los estados mentales tanto del terapeuta como del paciente se clarificaban 
todo el tiempo dentro de un vínculo terapéutico. Por el otro, en segundo lugar, el mismo paciente en una terapia que dejaba de lado ese tipo de intervenciones, sufriría.

Las personas buenas para entablar vínculos, de hecho se desempeñaron mejor en la terapia en intervenciones sin interpretaciones sobre la transferencia, es decir, si el terapeuta no hablaba sobre ambos (terapeuta y paciente) todo el tiempo, puesto que los distraía de lo que realmente querían hablar, que era ellos mismos. "¿Por qué siempre está pensando en usted? Soy yo en quien tendría que estar pensando. Sobre mí, yo soy el que está pagando".

Así que pienso que gran parte de nuestro trabajo, de nuestro énfasis en entrenar a los terapeutas para que trabajen la transferencia, es porque trabajamos principalmente con personas que tienen capacidades objetales pobres, y ahí sí, debemos trabajar en el vínculo para promover su capacidad para mentalizar.

\section{¿Qué características deberían de tener los terapeutas para trabajar con este tipo de pacientes?}

Nosotros llevamos a cabo una investigación sobre esto. Teníamos a un montón de sujetos, de hecho 12, candidatos que querían trabajar con nosotros, y los asignamos aleatoriamente a dos grupos: la mitad a un grupo donde iban a recibir cierto entrenamiento, la otra mitad a uno que no. Los candidatos eran psicólogos y psiquiatras con experiencia clínica con estos pacientes, y queríamos evaluar si existía alguna contribución específica de nuestro tipo de tratamiento. En ambos grupos, hubo terapeutas cuyos pacientes mejoraron más rápidamente. La diferencia entre los terapeutas no fue en última instancia cuánto mejoró el paciente, sino más bien la rapidez con la que el paciente mejoró. Algunos terapeutas generaron una mejoría muy rápida en sus pacientes, y algunos lo hicieron muy vagamente, es decir, lentamente, parecían tomarse su tiempo.

Esto es empírico; lo que puedo decirles conociendo a estos terapeutas, es algo muy sencillo. Los terapeutas que en general tienen una menor probabilidad de ponerse ansiosos con estos pacientes, son mucho mejores. Eso independientemente del resto de las variables como su formación, número de títulos, su género, su orientación terapéutica, nada de eso pesa tanto como qué tan asustados se ponen al sentarse frente a alguien que les dice: "está bien, Dr. Fonagy, pero me voy a tomar un montón de pastillas. ¿Qué va a hacer usted al respecto?". Y si el miedo se apodera del terapeuta, ahí es cuando la intervención comienza a bajar su ritmo de progreso. Y si les responden "Vamos a tratar de pensar al respecto un poco", están perdidos.

Nuestro manual dice que si un paciente llega y les dice: "Voy a tomarme un montón de pastillas", ¿qué tiene que responder el terapeuta?, nuestro manual dice de hecho, y es muy interesante, "Tenemos un plan en caso de crisis, que le di al principio de la terapia, así que hoy voy a terminar la sesión cinco minutos antes, y vamos a repasar el plan en caso de crisis, para asegurarnos de que va a estar bien, pero por ahora no quiero hablar al respecto, me gustaría hablar sobre cómo está todo en su vida. Así que, ¿qué está ocurriendo?".

Así que ustedes no lidian con amenazas, que normalmente tienen lugar, pero lo que tienen que hacer es decirles: "sí, bueno, vamos a hablar sobre eso después. Hablemos sobre usted y sobre mí, sobre lo que está ocurriendo." Y para mí, esa cualidad de no perturbarse fácilmente por el paciente, no dejar que la terapia se desvíe, no dejarse distraer o perder el plan de trabajo a la luz de alguien que quiere tomar el control de nuestra agenda de trabajo. Y para ese alguien es que uno debe ser alguien distinto a quien uno es realmente, porque si no, no resulta útil para el tratamiento de este tipo de pacientes.

¿Puedo finalizar con una anécdota? Una anécdota de cuando dejé que el paciente actuara de esa manera. Una anécdota que me dejó claro la manera en la que nunca debía haberme comportado al trabajar con pacientes como éste. Este paciente me estaba diciendo que yo no sabía lo que hacía, cosa que todos hacen; que yo no sabía lo que hacía, bien, pero me alteró cuando dijo que conocía a un analista kleiniano que era muy bueno trabajando con personas como ella. En ese punto, me desencajé tanto que hice una interpretación, algo así como "me parece que la relación que estamos construyendo, de alguna manera usted está tratando de destruirla". En ese momento, ella se levantó, tuvo la cortesía de detenerse en la puerta y decirme: "para mí, está relación está terminada; hasta luego" y se fue.

$Y$ entonces dije: mierda. Porque dije exactamente lo que imaginé que ese analista kleiniano diría. Si ustedes son así, no son buenos para trabajar con este tipo de personas. Después la 
paciente volvió a la próxima sesión y me dijo: "Lo siento mucho, debo haberlo molestado mucho. De verdad que no era mi intención", bla, bla, bla.
Esta historia tuvo un final razonablemente feliz, pero en fin, es el tipo de cosas que creo que no deberían hacerse. Muchas gracias.

\footnotetext{
${ }^{1}$ Conferencia dictada por el Prof. Dr. Peter Fonagy en ocasión de su visita a Montevideo en setiembre de 2011. Actividad organizada por la Maestría en Psicología Clínica del Niño y del Adolescente, Facultad de Psicología, Universidad Católica del Uruguay.

2 Peter Fonagy, Doctor en Psicología y miembro de la Real Academia Británica; Profesor de Psicoanálisis en el University College of London; Director Ejecutivo del Anna Freud Center; Psicoanalista Didáctico y Supervisor de la Sociedad Británica de Psicoanálisis. http://www.ucl.ac.uk/psychoanalysis/unit-staff/peter.html
}

Para citar esta Conferencia:

Fonagy, P. (2015). Uso de la mentalización en el proceso psicoanalítico. Ciencias Psicológicas 9(2): $179-196$ 